\title{
Caking Phenomena During Pilot-Scale Crystallization of Dextrose Monohydrate
}

\author{
Bayu Mahdi Kartika ${ }^{1,2^{*}}$, Harsojo Harsojo ${ }^{1}$, and Eriawan Rismana ${ }^{2}$ \\ ${ }^{1}$ Department of Physics, Faculty of Mathematics and Natural Science, Universitas Gadjah Mada, \\ Sekip Utara BLS 21, Yogyakarta 55281, Indonesia \\ ${ }^{2}$ Center for Pharmaceutical and Medical of Technology, Agency for Assessment and Application of Technology, \\ PUSPIPTEK Area, South Tangerang, Banten, Indonesia
}

\section{* Corresponding author:}

tel: $+62-87738938256$

email: bayu.mahdi@bppt.go.id

Received: September 23, 2020

Accepted: June 16, 2021

DOI: $10.22146 / \mathrm{ijc} .60095$

\begin{abstract}
Dextrose Monohydrate (DMH) is a bulk chemical used in the food, beverage, and pharmaceutical industries. The caking often appeared in the crystallization of DMH. Caking is an agglomeration that can affect the product quality of DMH and is dependent on the type of impeller. This study aimed to determine the type of impeller to avoid the caking during the DMH crystallization and identify the DMH caking. The results showed that caking did not occur on the helical ribbon and anchor impeller, while caking appeared on the Rushton turbine impeller. Computational fluid mechanics (CFD) analysis showed that caking occurs due to uneven homogeneity of stirring. Fourier transform infrared (FTIR) and X-ray diffraction (XRD) studies showed that DMH caking and non-caking had the same peak pattern. Meanwhile, optical microscope and scanning electron microscope (SEM) analysis showed that the DMH caking seen agglomerate. Density analysis showed that DMH with caking was $1.257-1.350 \mathrm{~kg} / \mathrm{L}$, while the noncaking was $0.504-0.780 \mathrm{~kg} / \mathrm{L}$. Caking phenomena during the DMH crystallization can be avoided by using a helical ribbon and anchor impeller. FTIR and XRD analysis cannot be used to identify DMH caking products; meanwhile, optical microscope, SEM, and density analyzes can be used to identify DMH caking products.
\end{abstract}

Keywords: caking; crystallization; dextrose monohydrate; impeller

\section{- INTRODUCTION}

Dextrose Monohydrate (DMH) is a bulk chemical used in the food, beverage, and pharmaceutical industries. In the food and beverage industry, DMH is used as an alternative sweetener to sucrose. Meanwhile, in the pharmaceutical industry, $\mathrm{DMH}$ is an active ingredient or an additive (excipient) to pharmaceutical products, such as tablets and capsule syrup. DMH food-grade refers to Indonesian National Standard (SNI) 4591-2010 [1], DMH pharmaceutical-grade refers to Indonesian Pharmacopoeia Volume V [2], and United State Pharmacopeia (USP) [3]. Dextrose is a monosaccharide derived from polysaccharides (amylose and amylopectin in starch). Srisa-Nga et al. [4] reported that dextrose has three forms, which is $\alpha$ dextrose monohydrate $\left((-5)-50{ }^{\circ} \mathrm{C}\right)$, $\alpha$-dextrose anhydrous $\left(50-115^{\circ} \mathrm{C}\right)$, and $\beta$-dextrose anhydrous $\left(115-150{ }^{\circ} \mathrm{C}\right)$. Dextrose has three forms due to the influence of temperature during the crystallization process. The chemical structure of DMH is $\mathrm{C}_{6} \mathrm{H}_{12} \mathrm{O}_{6} \cdot \mathrm{H}_{2} \mathrm{O}$, and dextrose anhydrous is $\mathrm{C}_{6} \mathrm{H}_{12} \mathrm{O}_{6}$. Zheng et al. [5] reported $\mathrm{DMH}$ had a monoclinic crystal form with a primitive axis vector $\mathrm{a}=8.803 \AA$, $\mathrm{b}=5.085 \AA, \mathrm{c}=9.708 \AA$, with angle $\alpha=\gamma=90^{\circ} \neq \beta$. Dextrose anhydrous had an orthorhombic crystal form with a primitive axis vector $\mathrm{a}=10.366 \AA$, $\mathrm{b}=14.851 \AA, \mathrm{c}=4.975 \AA$, with angle $\alpha=\beta=\gamma=90^{\circ}$.

$\mathrm{DMH}$ production went through the dilution process, the crystallization process, the separation process, and the drying process. Crystallization is a crucial process in DMH production. It determines the size, morphology of the crystal shape, and quality of DMH products (Table 1). Crystallization is the process of forming crystalline solids from saturated solutions that have high purity. Many scientists reported the crystallization process. Frawley et al. [6] reported the

Bayu Mahdi Kartika et al. 
Table 1. Standard requirements for dextrose monohydrate

\begin{tabular}{|c|c|c|c|}
\hline Parameters & Unit & Food grade ${ }^{\star}$ & Pharmaceutical grade ${ }^{\star *}$ \\
\hline Description & - & Powder, white, sweet & Powder, white, sweet \\
\hline Solubility & - & Soluble in water & Soluble in water \\
\hline Optical rotation & - & $+52.6^{\circ}$ to $+53.2^{\circ}$ & $+52.6^{\circ}$ to $+53.2^{\circ}$ \\
\hline Acidity & - & 3.2 to 6.5 & 3.2 to 6.5 \\
\hline Amylum test & - & Negative & Negative \\
\hline Pyrogen free & - & - & Negative \\
\hline Dextrose equivalent & $\%(w / w)$ & 95 to 105 & 95 to 105 \\
\hline Water content & $\%(\mathrm{w} / \mathrm{w})$ & 7.5 to 9.5 & 7.5 to 9.5 \\
\hline Sulphate & $\mathrm{mg} / \mathrm{kg}$ & Max. 250 & Max. 250 \\
\hline Chloride & $\mathrm{mg} / \mathrm{kg}$ & Max. 180 & Max. 180 \\
\hline \multicolumn{4}{|l|}{ Metal contamination } \\
\hline - Lead (Pb) & $\mathrm{mg} / \mathrm{kg}$ & Max. 0.5 & Max. 0.5 \\
\hline - Copper $(\mathrm{Cu})$ & $\mathrm{mg} / \mathrm{kg}$ & Max. 10 & Max. 10 \\
\hline - Zinc (Zn) & $\mathrm{mg} / \mathrm{kg}$ & Max. 25 & Max. 25 \\
\hline - Arsenic (As) & $\mathrm{mg} / \mathrm{kg}$ & Max. 1 & Max. 1 \\
\hline \multicolumn{4}{|c|}{ Microbial contamination } \\
\hline - Total plate count & colony/g & Max. 100 & Max. 100 \\
\hline - Mold and yeast & colony/g & Max. 10 & Max. 10 \\
\hline - Escherichia coli & colony/g & Negative & Negative \\
\hline - Salmonella & colony/g & Negative & Negative \\
\hline
\end{tabular}

development of supersaturation, temperature, agitation, and seeds on the nucleation of paracetamol. Acevedo and Nagy [7] had observed the effect of crystallization without seed on the size and form of the crystal. El-Yafi and ElZein [8] reported several factors that influence the crystallization process of pharmaceutical bulk. Jha et al. [9] and Besenhard et al. [10] reported the modeling and controlling of the crystallization process. Sormoli et al. [11] and Tappi et al. [12] reported crystallization behavior during water induced. Parimaladevi and Srinivasan [13] reported the influence of supersaturation solution on the crystallization process. On the other hand, many studies on the crystallization of DMH have been reported. They include the effect of impurities during the crystallization process [14], the impact of initial solution concentration, seed, and cooling profile [15], growth kinetics of the crystallization [16], modeling and controlling system of the crystallization process [17], as well as the crystallization of starch [18].

The caking often occurs in the crystallization process.
Caking is an agglomeration process that influences the quality of products, size, and crystal morphology. Carpin et al. [19] reported the lactose caking; Langlet et al. [20] reported the caking in sodium chloride $(\mathrm{NaCl})$; Freeman et al. [21] reported the measurement of caking durability; Afrassiabian et al. [22] reported the capillary condensation in caking; Zafar et al. [23] reviewed the bulk powder caking; Chen et al. [24] reported the prevention of caking, Chen et al. [25] reported the amorphous and humidity caking, and Lipasek et al. [26] reported the effect of anticaking agent and storage on caking phenomena. Chen et al. [25] have discussed amorphous caking and humidity caking. Amorphous caking occurs in amorphous particles and appears when the ambient temperature is higher than the temperature of the glass transition material. It causes a sintering bridge, which is a bridge connecting the amorphous particles. It is also reported that humidity caking occurs in amorphous and crystalline particles. Humidity caking occurs due to differences in relative humidity (RH). $\mathrm{RH}$ 
causes capillary condensation or deliquescence. Capillary condensation causes a liquid bridge between particles; meanwhile, deliquescence causes a liquid bridge between particles and coats at the particles. Capillary condensation and deliquescence absorb water from the environment [25].

This study aimed to determine the type of impeller to avoid the caking during the crystallization of $\mathrm{DMH}$. The crystallization can produce $\mathrm{DMH}$, which complied with the standard requirements in Table 1. This study used three types of the impeller. They were Rushton turbine, helical ribbon, and anchor impeller. The selection of those three is based on the type of impeller, often used on an industrial scale. Based on the preliminary research, homogeneity of stirring had the most significant effect on the caking phenomenon. Sinnott [27] reported that the shape and size of the impeller affected the homogeneity of the stirring. This study also aimed to identify the $\mathrm{DMH}$ caking use some analyzes. The analyzes were analysis process, computational fluid mechanics (CFD) analysis, optical microscope analysis, scanning electron microscope (SEM) analysis, density analysis, Fourier transform infrared (FTIR) analysis, and x-ray diffraction (XRD) analysis.

\section{- EXPERIMENTAL SECTION}

\section{Materials}

The bulk chemical was used DMH food-grade $\left(\mathrm{C}_{6} \mathrm{H}_{12} \mathrm{O}_{6} \cdot \mathrm{H}_{2} \mathrm{O}\right)$ from PT Qinhuangdao Lihua StarchChina with a purity of $99.7 \%$ and a moisture content of $8.20 \%$. The seed was used DMH pharmaceutical grade with a purity of $100.3 \%$ and a moisture content of $9.57 \%$. It was from the Center for Pharmaceutical and Medical of Technology, Agency for Assessment and Application of Technology. The seed size was 63-177 $\mu \mathrm{m}$ (630-80 mesh size). Reverse Osmosis (RO) water was used as the solvent.

\section{Instrumentation}

The tool used for the dilution and crystallization process was a double jacketed crystallizer. The double jacketed system was used for the temperature of the crystallizer. The crystallizer has $37 \mathrm{~cm}$ in diameter, $40 \mathrm{~cm}$ in height and was curved at the bottom. There are three types of impeller used in this study, Rushton turbine, helical ribbon, and anchor. The Rushton turbine has a diameter of $15.5 \mathrm{~cm}$ and a 6 -sided baffle. Each baffle was $4.8 \mathrm{~cm}$ long and $3.3 \mathrm{~cm}$ high. The helical ribbon was $36 \mathrm{~cm}$ long and $20.5 \mathrm{~cm}$ tall, while the anchor was $36 \mathrm{~cm}$ long and $39.5 \mathrm{~cm}$ high. Crystallizer and three types of impeller were made of stainless steel (SS) 316. The equipment used for the separation process is a centrifuge with a filter system, with a capacity of $60 \mathrm{~L}$ and an agitation speed was $1,200 \mathrm{rpm}$. The tools used for the drying process were a vertical fluidized bed dryer (FBD) with a capacity of $17 \mathrm{~L}$ and a milling device with a capacity of $5 \mathrm{~L}$ with a filter size of $1190 \mu \mathrm{m}$ (16 mesh size).

The Atago refractometer measured the Brix value of glucose solution with a $0-85 \%$ measurement range. The Solidworks software was used for computational fluid mechanics. The optical microscope was used by the Axiostar Plus brand and the Axiocam 105 Color camera. SEM was used FEI Quanta model 650. The Thermo Scientific Nicolet iS10 used FTIR spectroscopy with iD7 attenuated total reflectance (ATR) mode. The XRD was used by the Malvern Panalytical Benchtop brand, the Aeris Research model.

\section{Procedure}

\section{Crystallization process}

DMH food-grade from China $(22.6 \mathrm{~kg})$ was dissolved using $\mathrm{RO}$ water $(5.4 \mathrm{~kg})$ at $80^{\circ} \mathrm{C}$. The result of the dilution was glucose solution with a Brix value of $\pm 70 \%$. The crystallization process used three types of the impeller: Rushton turbine, helical ribbon, and anchor. Crystallization began when the seed was added, an agitation speed of $40 \mathrm{rpm}$, at room temperature (29$30{ }^{\circ} \mathrm{C}$ ) for $24 \mathrm{~h}$. The seeds were added $1 \%(280 \mathrm{~g})$ by the weight of the glucose solution. The selection of crystallization conditions was based on Markande et al. [12-14] and Flood and Srisanga [28]. The crystallization on each impeller was twice. Sampling was carried out every four hours during the crystallization process. Crude DMH and mother liquor were separated using a centrifuge laboratory scale with a rotation speed of $2,300 \mathrm{rpm}$, temperature $20^{\circ} \mathrm{C}$ for $30 \mathrm{~min}$. Crude $\mathrm{DMH}$

Bayu Mahdi Kartika et al. 
was analyzed using an optical microscope. Sampling every four hours was carried out to see the movement of the size and morphology of the crystals in DMH caking and noncaking during the crystallization process.

DMH caking cannot be continued to the separation and drying process due to the rigid structure. Slurry DMH (non-caking) was treated in the separation and drying process. The centrifuge is used to separate crude $\mathrm{DMH}$ and mother liquor. DMH slurry was put into a centrifuge with a rotating speed of 1,200 rpm, room temperature 29$30{ }^{\circ} \mathrm{C}$ for $30 \mathrm{~min}$. The weight of crude $\mathrm{DMH}$ was measured. The mother liquor was measured by weight and Brix value. Crude DMH dried using a fluidized bed dryer (FBD) at a temperature of $50{ }^{\circ} \mathrm{C}$ for $60 \mathrm{~min}$. FBD was used to reduce water content in crude DMH. Crude $\mathrm{DMH}$ was processed using milling. Milling is used for producing DMH products of uniform size. The production of the DMH process was described in Fig. 1.

\section{Analysis}

$\mathrm{DMH}$ products were analyzed using process analysis, density analysis, optical microscope analysis, SEM analysis, FTIR analysis, and XRD analysis. The $\mathrm{DMH}$ products analyzed were DMH caking after the crystallization, and DMH non-caking had been separated and dried. The crystallization process yield analysis was calculated using Eq. (1), where $\mathrm{M}_{\mathrm{c}}$ represents the weight of DMH crude $(\mathrm{kg}), \mathrm{M}_{\mathrm{s}}$ is the weight of seed $(\mathrm{kg})$, and $\mathrm{M}_{\mathrm{r}}$ is the weight of $\mathrm{DMH}$ raw material $(\mathrm{kg})$. The yield calculation is based on the weight of the crude $\mathrm{DMH}$, seed, and raw material.

Yield $=\frac{M_{c}-M_{s}}{M_{r}} \times 100 \%$

Computational fluid mechanics (CFD) analysis was used to simulate the solution's movement in $\mathrm{DMH}$ crystallization. The CFD used the same conditions during the crystallization of $\mathrm{DMH}$, including the impeller's dimensions and the crystallizer, the impeller material and the crystallizer chamber, the agitation speed, the height of the glucose solution, and the impeller position. An optical microscope and SEM analysis were used to determine the morphology of DMH crystals. DMH samples were analyzed by using an optical microscope with a magnification of 100 times. The preparation sample for

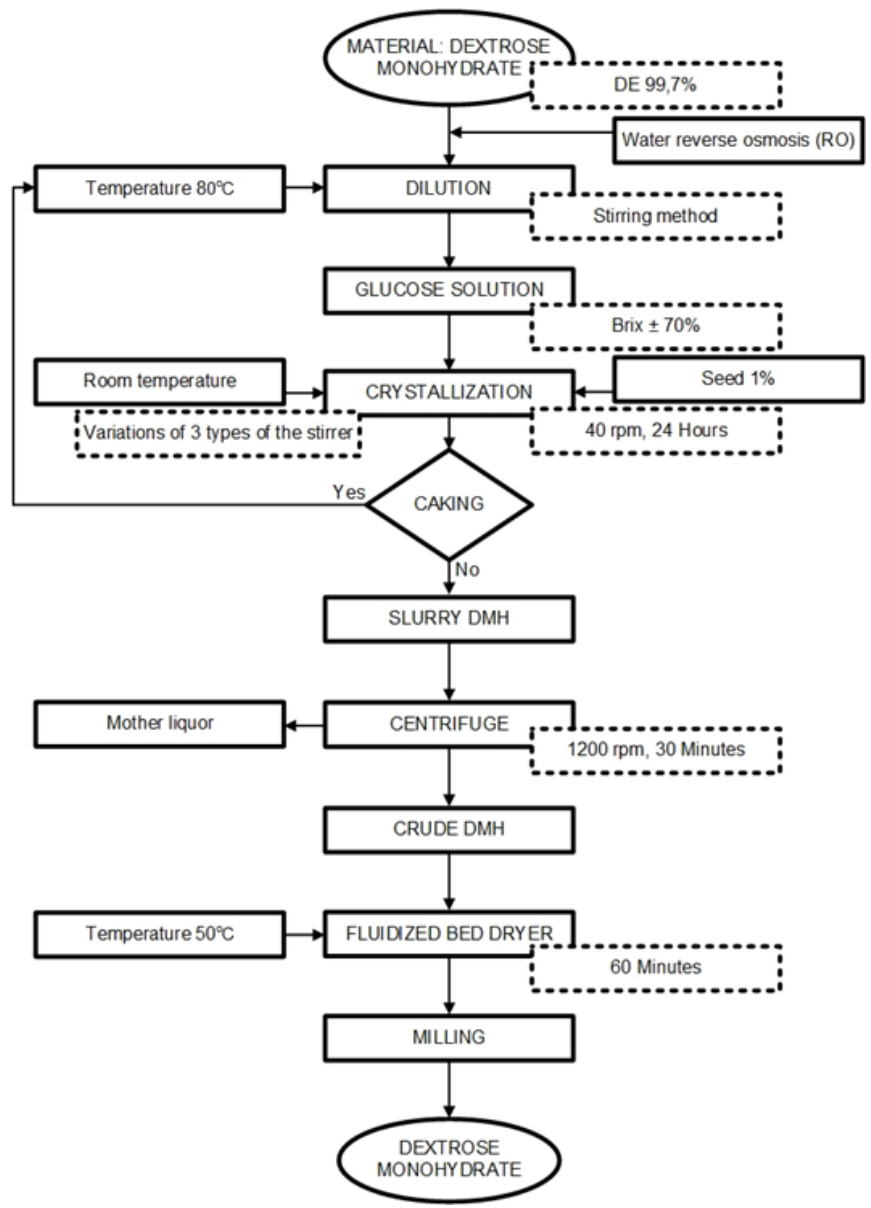

Fig 1. Flow chart of Dextrose Monohydrate production

SEM analysis was coated using gold for $80 \mathrm{sec}$. SEM analysis was performed with the magnification of 100 and 500 times. Density analysis of DMH solid was measured by dividing the weight $(\mathrm{g})$ by the volume $(\mathrm{mL})$. Five grams of DMH solid were put into a graduated cylinder containing $10 \mathrm{~mL}$ of ethanol. The difference in volume value was calculated as the volume of DMH solid. According to Indonesia Pharmacopeia Volume V [2], DMH was insoluble in ethanol. Density measurements were done twice, and the average value was taken.

FTIR was used for functional group vibration analysis. FTIR has used the ATR method with a wavenumber range of $400-4000 \mathrm{~cm}^{-1}$ and a resolution of $8 \mathrm{~cm}^{-1}$. Fifty $\mathrm{mg}$ of DMH samples were used for each FTIR analysis. XRD was used for crystallinity analysis. DMH samples were prepared in powder. It was measured in the range of $2 \theta$ between 5-90 with $\lambda_{(\mathrm{Kal})}=$ 
$1.540598 \AA$. The anode material was used copper $(\mathrm{Cu})$ with a scan step size of $0.022^{\circ} /$ step and time per step 23.97 s/step. The XRD analysis was compared with the XRD by Hough et al. [29] from the Cambridge Crystallographic Data Center (CCDC) using the Rietveld Refinement method Reitica software.

\section{- RESULTS AND DISCUSSION}

\section{Process Analysis}

$\mathrm{DMH}$ production has been carried out in six crystallization experiments, three variations of the impeller, and two repetitions of each impeller. Fig. 2 is an analysis of the crystallization of DMH. Fig. 2(a) shows that the Rushton turbine produces DMH caking. DMH caking due to an agglomeration process. DMH caking could not proceed to the separation and drying process. It is due to its rigid structure. The helical ribbon and anchor impeller (Fig. 2(b) and Fig. 2(c)) produce DMH noncaking. DMH non-caking is marked by unprecedented agglomeration (slurry DMH). DMH non-caking (helical ribbon and anchor) can proceed to the separation and drying process.

Table 2 summarizes the experimental data for the crystallization of DMH. The results show that the caking only occurs on the Rushton turbine impeller. In contrast, the anchor and helical ribbon impellers do not cause caking. DMH caking is marked by having no yield and mother liquor. It is due to agglomeration during crystallization (Fig. 2(a)). Table 2 shows that the anchor and helical ribbon impellers do not cause caking, marked by having any agglomeration (Fig. 2(b) and Fig. 2(c)). DMH non-caking had a yield between 45.00$49.46 \%$. DMH non-caking has proceeded to the separation process so that a by-product was obtained in the form of mother liquor. The anchor's yields are $47.86 \%$ and $46.07 \%$. The mother liquor are $49.68 \%$ (Brix $62.20 \%$ ) and 47.21 (Brix 62.10\%). The helical ribbon's yields are $49.46 \%$ and $45.00 \%$. The mother liquor is
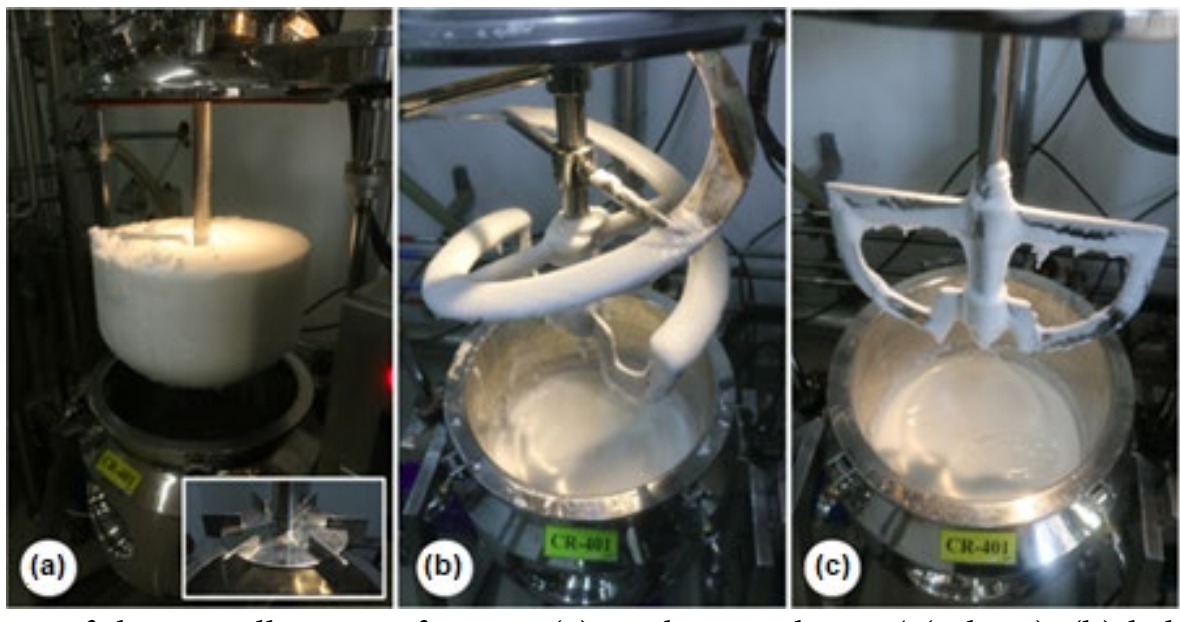

Fig 2. The appearance of the crystallization of DMH; (a) Rushton turbine $1^{\text {st }}$ (caking), (b) helical ribbon $1^{\text {st }}$ (noncaking), and (c) anchor $1^{\text {st }}$ (non-caking)

Table 2. Experimental data for crystallization of dextrose monohydrate

\begin{tabular}{cccccc}
\hline Code & Impeller & Caking & Yield (\%) & ML $^{\star}(\%)$ & Brix ML (\%) \\
\hline K.02.02 & ${\text { Rushton turbine } 1^{\text {st }}}^{\text {R }}$ & Caking & - & - & - \\
K.01.03 & Rushton turbine 2 $^{\text {nd }}$ & Caking & - & - & - \\
K.04.02 & Anchor 1 $^{\text {st }}$ & Non-caking & 47.86 & 49.68 & 62.30 \\
K.02.03 & Anchor 2 $^{\text {nd }}$ & Non-caking & 46.07 & 47.21 & 62.10 \\
K.03.02 & Helical ribbon 1 $^{\text {st }}$ & Non-caking & 49.46 & 46.68 & 61.10 \\
K.03.03 & Helical ribbon 2 & Non-caking & 45.00 & 52.86 & 60.00 \\
\hline
\end{tabular}

* $=$ Mother liquor $\%(w / w)$

Bayu Mahdi Kartika et al. 
46.68\% (Brix 61.10\%) and 52.86\% (Brix 60.00\%). The yielding process and mother liquor were added. It is less than $100 \%$ due to the loss of the process when taking the slurry DMH. It is left in the crystallizer chamber due to the slurry DMH is sticky.

\section{Computational Fluid Mechanics Analysis}

Computational fluid mechanics (CFD) analysis uses SolidWorks software. It aims to simulate the movement of fluid in the crystallization of DMH. The CFD analysis uses the same conditions in the crystallization of DMH, which are dimensions of the impellers and crystallizer chamber, the material for impellers and the crystallizer chamber, the speed of stirring rotation, the height of the glucose solution, and the position of the impeller. The CFD analysis shows that the Rushton turbine impeller (Fig. 3(a) and Fig. 3(d)) produces uneven homogeneity of stirring since the Rushton turbine cannot reach all areas of the solution. It is indicated by the blue color area (0$2.571 \mathrm{~m} / \mathrm{s}$ ) on the surface of the solution (Fig. 3(d)).

The helical ribbon (Fig. 3(b) and (e)) and anchor impellers (Fig. 3(c) and (f)) show an even homogeneity of stirring. It is due to the impeller can reach all areas of the solution. The homogeneity is indicated by red (9.429$12.000 \mathrm{~m} / \mathrm{s})$, yellow $(7.714-9.429 \mathrm{~m} / \mathrm{s})$, green $(4.286-$
$7.714 \mathrm{~m} / \mathrm{s})$, and light blue (2.571-4.286 m/s) color on the surface of the solution. It has a high fluid flow rate. According to Sinnott [27], helical ribbon and anchor are more suitable for use in solutions that had a high viscosity $\left(>6 \times 10^{1} \mathrm{Ns} / \mathrm{m}^{2}\right)$ than the Rushton turbine used in a lower viscosity $\left(10^{0}-10^{1} \mathrm{Ns} / \mathrm{m}^{2}\right)$ (Fig. 3(b) and Fig. 3(c)). Fig. 3(b) shows that the fluid flow is evenly distributed in all parts, marked in light blue. Fig. 3(c) shows the fastest fluid flow is only near the impeller, kept in red and yellow around the impeller only. So, it is apparent that the helical ribbon impeller has a more even stirring homogeneity than the anchor impeller.

\section{Optical Microscope Analysis}

Optical microscope analysis is used to see the morphology of the crystal form of DMH products. Fig. 4 is the optical microscope analysis on six crystallizations of DMH. Fig. 4(a) and (d) show DMH caking, while Fig. 4(b), (c), (e), and (f) show DMH products do not cause agglomeration (non-caking). Fig. 5 shows the $\mathrm{DMH}$ caking movement on the Rushton turbine $1^{\text {st }}($ K.02.02) from 4 to $24 \mathrm{~h}$. At four hours of the crystallization process, a caking has occurred due to the agglomeration. Fig. 5 shows that caking occurs early in the crystallization process, continuing to $24 \mathrm{~h}$. Fig. 6 shows
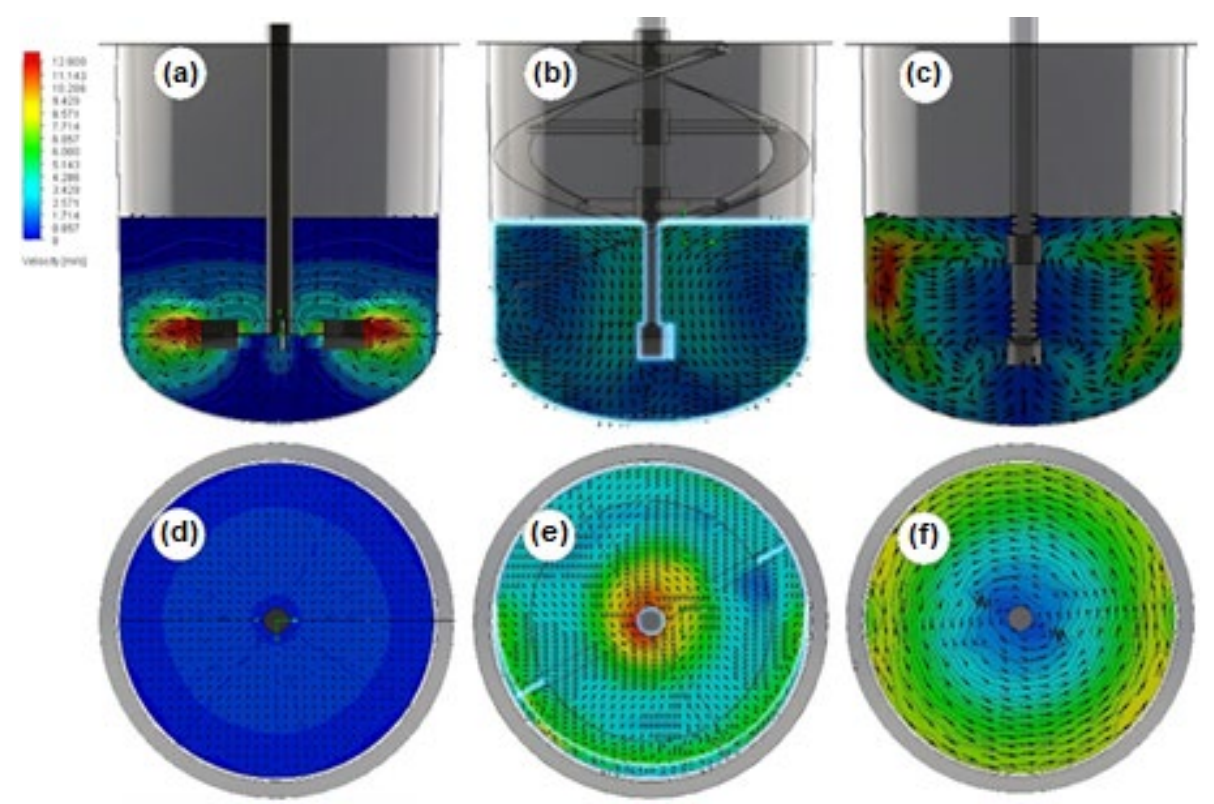

Fig 3. Computational fluid mechanics on the three impellers; side view (a) Rushton Turbine, (b) Helical Ribbon, (c) Anchor and Top View of (d) Rushton Turbine, (e) Helical Ribbon, and (f) Anchor 


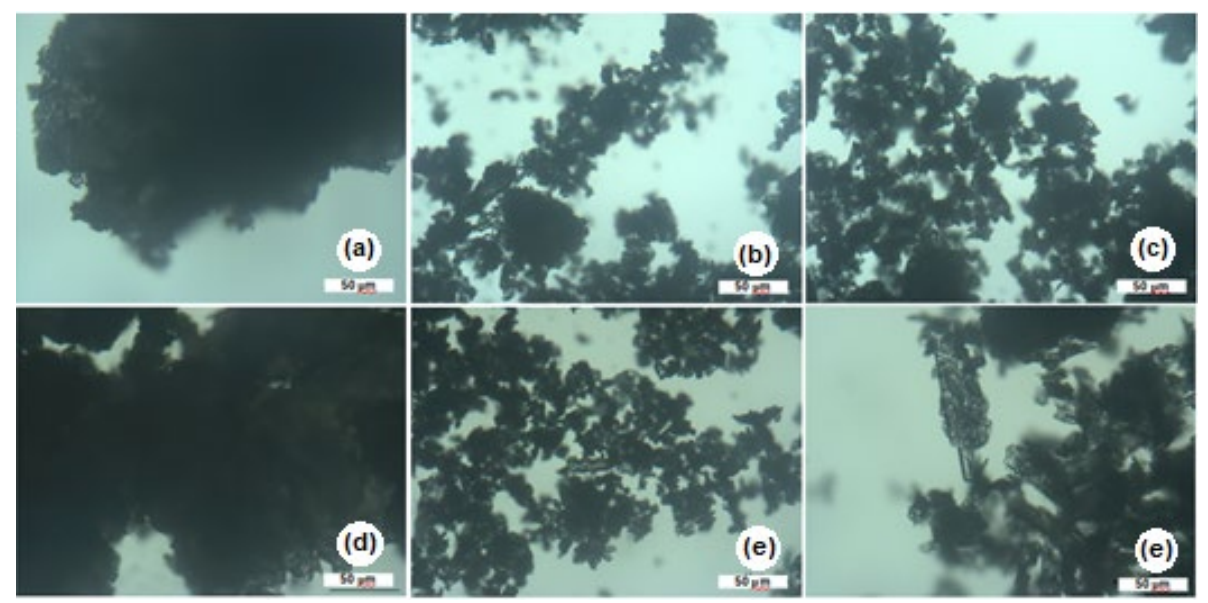

Fig 4. Appearance of the optical microscope with a magnification of 100 times; (a) K.02.02 (Rushton turbine $1^{\text {st }}$ ), (b) K.04.02 (anchor $1^{\text {st }}$ ), (c) K.03.02 (helical ribbon $1^{\text {st }}$ ), (d) K.01.03 (Rushton turbine $2^{\text {nd }}$ ), (e) K.02.03 (anchor $2^{\text {nd }}$ ) and (f) K.03.03 (helical ribbon $2^{\text {nd }}$ )
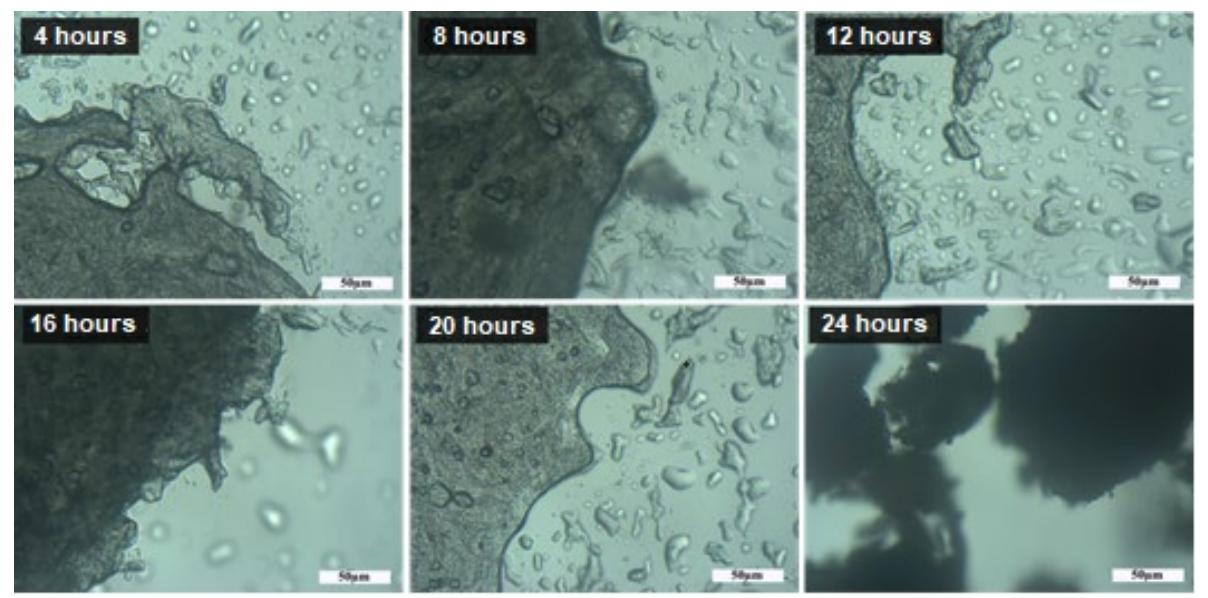

Fig 5. The process of caking crystal on the crystallization of DMH (K.02.02)

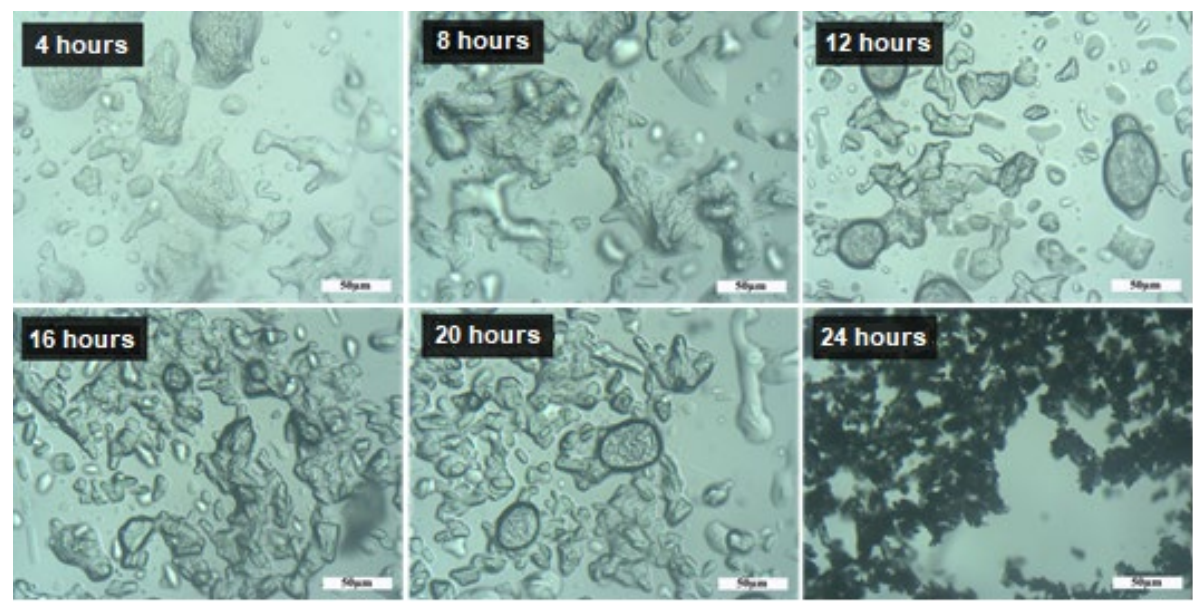

Fig 6. Process of non-caking crystal on the crystallization of DMH (K.03.02) 
the movement of the crystals during the crystallization of DMH. At four hours of the crystallization, it is seen that the DMH crystal is still small. It began giant crystal up to $24 \mathrm{~h}$. DMH can do growth if it does not involve agglomeration (non-caking). Optical microscope analysis can be used to identify the DMH caking due to the visible agglomerate.

\section{Density Analysis}

Table 3 summarizes the results of analysis of the density values of glucose solution $70 \%$ Brix (raw material), DMH caking (Rushton turbine $2^{\text {nd }}$ ), DMH noncaking (helical ribbon $2^{\text {nd }}$ and anchor $2^{\text {nd }}$ ), and $\mathrm{DMH}$ standard (Merck). The density of glucose solution is $1.350 \mathrm{~kg} / \mathrm{L}, \mathrm{DMH}$ caking is $1.257 \mathrm{~kg} / \mathrm{L}, \mathrm{DMH}$ non-caking (helical ribbon $2^{\text {nd }}$ ) is $0.507 \mathrm{~kg} / \mathrm{L}$, of $\mathrm{DMH}$ non-caking (anchor $2^{\text {nd }}$ ) is $0.708 \mathrm{~kg} / \mathrm{L}$ and DMH Merck is $0.606 \mathrm{~kg} / \mathrm{L}$. The density value of DMH caking is close to the glucose solution (as a raw material). Meanwhile, the density of DMH non-caking (helical ribbon $2^{\text {nd }}$ and anchor $2^{\text {nd }}$ ) has a small difference from that of DMH Merck. DMH caking has a bigger density than $\mathrm{DMH}$ non-caking due to the agglomeration. DMH caking absorbs much water to have a rigid structure (see Fig. 2(a)).
Fig. 7 shows DMH non-caking and DMH caking after storage in a closed container for eight weeks. DMH non-caking is white and powdery (Fig. 7(a)), while DMH caking is a yellow color, agglomerate, and grows fungus (Fig. 7(b)). Based on Table 1, DMH caking does not qualify since it is not powdery (agglomerate), has a yellow color, and grows fungus. The appearance of fungus is due to the high-water content of DMH caking, so that the density analysis can be used to identify DMH caking.

\section{SEM Analysis}

Based on the process analysis, CFD analysis, and optical microscope analysis, two experimental samples were selected, representing DMH caking (Rushton turbine $2^{\text {nd }}$ ) and DMH non-caking (helical ribbon $2^{\text {nd }}$ ). SEM analysis can be used to identify the DMH caking due to the agglomeration process. Fig. 8 is SEM analysis on DMH caking and non-caking with the magnification of 100 and 500 times. Fig. 8(b) and (d) show that DMH caking and non-caking have the same crystal form. It is monoclinic [5] (vector $\mathrm{a} \neq \mathrm{b} \neq \mathrm{c}$, with the angle of $\mathrm{a}=\gamma=$ $\left.90^{\circ} \neq \beta\right)$. However, the agglomeration process occurred (see Fig. 8(a)). Meanwhile, on DMH non-caking, agglomeration did not occur (Fig. 8(c)).

Table 3. Density measurement of dextrose

\begin{tabular}{lcc}
\hline \multicolumn{1}{c}{ Dextrose } & Impeller & Density $(\mathrm{kg} / \mathrm{L})$ \\
\hline Glucose solution Brix $\pm 70 \%$ & - & 1.350 \\
DMH caking & Rushton turbine 2 & 1.257 \\
DMH non-caking & Helical ribbon 2 $^{\text {nd }}$ & 0.504 \\
& Anchor 2 & 0.780 \\
DMH standard Merck & - & 0.606 \\
\hline
\end{tabular}
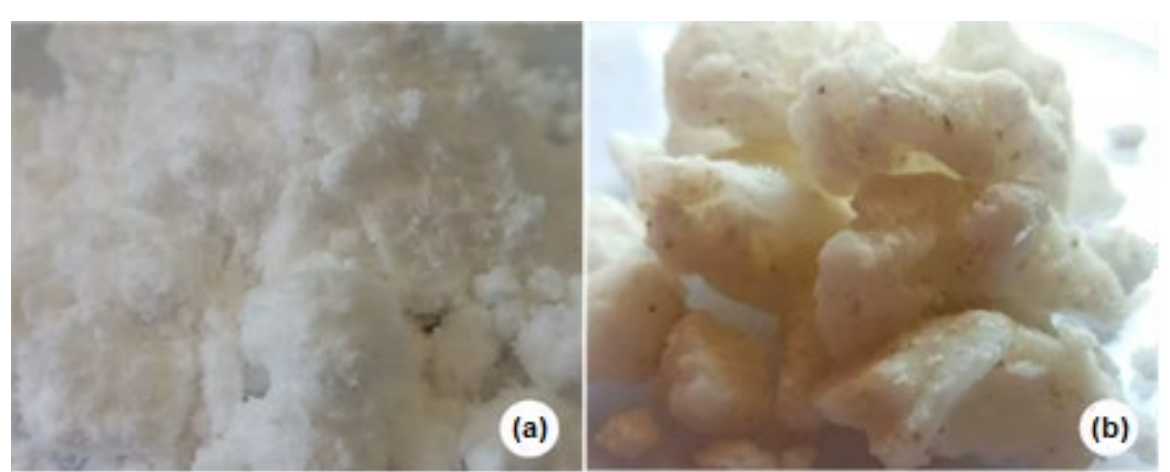

Fig 7. The appearance of (a) DMH non-caking K.03.03 and (b) DMH caking K.01.03 after storage in a closed container for eight weeks 


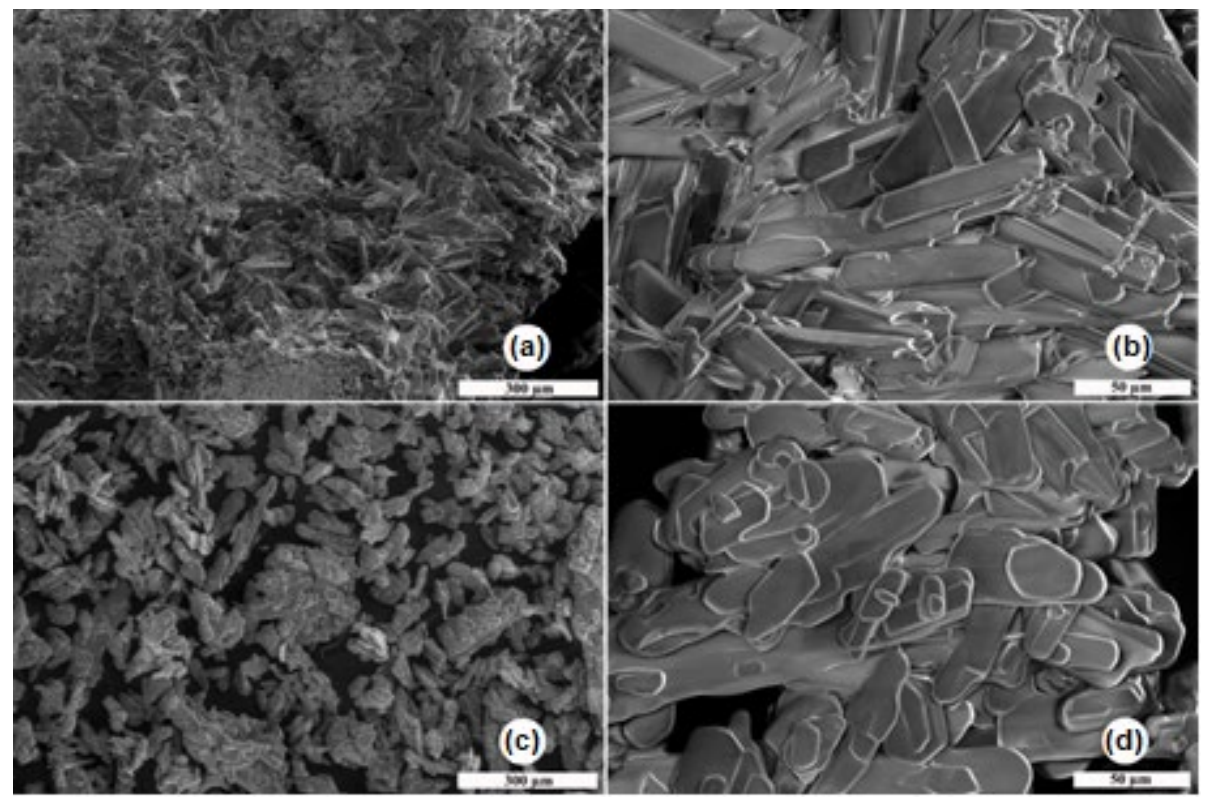

Fig 8. Appearance of crystal by SEM; DMH caking K.01.03 (a) magnification of 100 times, (b) magnification of 500 times, and DMH non-caking K.03.03 (c) magnification of 100 times, and (d) magnification of 500 times

\section{FTIR Analysis}

Fig. 9 shows the FTIR spectrum on DMH K.02.02 (Rushton turbine $1^{\text {st }}$ ), K.03.02 (helical ribbon $1^{\text {st }}$ ), K.04.02 (anchor $1^{\text {st }}$ ), K.01.03 (Rushton turbine $2^{\text {nd }}$ ), K.02.03 (anchor $2^{\text {nd }}$ ), and K.03.03 (helical ribbon $2^{\text {nd }}$ ). The six samples have the same peak pattern. The FTIR spectrum of DMH caking has a higher intensity than $\mathrm{DMH}$ non-caking. This is due to the density value of DMH caking $(1.257-1.350 \mathrm{~kg} / \mathrm{L})$ is higher than DMH non-caking $(0.504-0.780 \mathrm{~kg} / \mathrm{L})$ (Table 3). A higher density value produces a higher concentration so that the intensity of the DMH caking spectrum is higher than DMH non-caking. In DMH caking, a new peak appears at a wavenumber of $1643 \mathrm{~cm}^{-1}$. Wiercigroch et al. [30] reported that wavenumbers $400-1500 \mathrm{~cm}^{-1}$ is the fingerprint area with a single bond from $\mathrm{C}-\mathrm{O}, \mathrm{C}-\mathrm{C}$, and $\mathrm{C}-\mathrm{N}$. The wavenumbers of $1500-2000 \mathrm{~cm}^{-1}$ are the

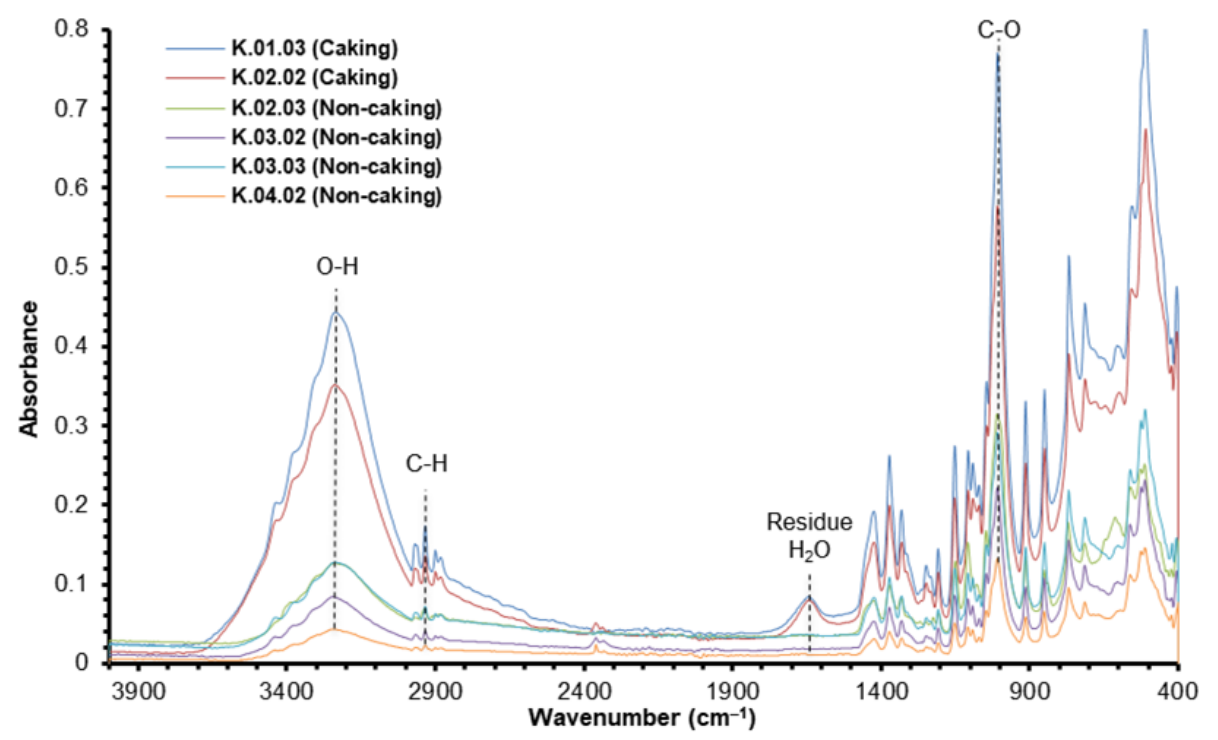

Fig 9. FTIR spectra on DMH caking of Rushton turbine $1^{\text {st }}(\mathrm{K} .02 .02)$ and Rushton turbine $2^{\text {nd }}(\mathrm{K} .01 .03)$, DMH noncaking on helical ribbon $1^{\text {st }}(K .03 .02)$, helical ribbon $2^{\text {nd }}(K .03 .03)$, the anchor $1^{\text {st }}(K .04 .02)$ and anchor $2^{\text {nd }}(K .02 .03)$ 
double bond area of $\mathrm{C}=\mathrm{O}$ and $\mathrm{C}=\mathrm{C}$. Meanwhile, Tokoro et al. [31] reported that the new peak on the wavenumber $1643 \mathrm{~cm}^{-1}$ corresponds to the water residue $\left(\mathrm{H}_{2} \mathrm{O}\right)$. Chen et al. [25] that the liquid bridge between the particles appears by absorbing much water. The water residue which appears in the DMH caking spectrum is due to the agglomeration. FTIR analysis cannot identify DMH caking because DMH caking and DMH non-caking have the same peak pattern.

\section{XRD Analysis}

Fig. 10 compares the XRD diffractogram on DMH caking (K.01.03) and DMH non-caking (K.03.03). DMH caking and non-caking have the same diffractogram peak pattern, which differs in some high-intensity peaks. They are at $2 \theta=9.5^{\circ}, 12.9^{\circ}, 18.7^{\circ}, 19.9^{\circ}, 20.4^{\circ}, 23.0^{\circ}$, and $28.5^{\circ}$. Significant differences are observed at $19.9^{\circ}$ and $20.4^{\circ}$. $\mathrm{DMH}$ non-caking has a higher peak than DMH caking. Hough et al. [29] reported that $\mathrm{DMH}$ had the three highest peaks at $19.7^{\circ}$ (high), $20.2^{\circ}$ (high), and $22.8^{\circ}$ (medium). XRD of DMH caking and non-caking have the same peak pattern due to the SEM analysis (Fig. 8(b) and Fig. 8(d)). XRD analysis cannot identify DMH caking because $\mathrm{DMH}$ caking and $\mathrm{DMH}$ non-caking have the same peak diffractogram pattern.

The XRD of DMH analysis using the Rietveld refinement. The XRD DMH caking (K.01.03) and noncaking (K.03.03) were compared to XRD DMH from
Hough et al. [29]. The XRD pattern of DMH in Ref. is taken from Cambridge Crystallographic Data Center (CCDC) in a crystallography information file (CIF). The Rietveld refinement uses Rietica software. Fig. 11 and Fig. 12 are the Rietveld refinement analysis results between DMH caking and non-caking compared to XRD from Hough et al. [29], which has the highest peaks at $2 \theta=19.9^{\circ}$ and $20.4^{\circ}$. The Rietveld refinement analysis results show that $\mathrm{DMH}$ caking and non-caking had the same peak pattern as the DMH from Ref. [26]. Thus, it is clear that DMH caking and non-caking have the same crystal form (monoclinic with vector $\mathrm{a} \neq \mathrm{b} \neq \mathrm{c}$, and the angle of $\alpha=\gamma=90^{\circ} \neq \beta$ ) as DMH from Hough et al. [26].

Sujiono et al. [32] reported standard value of the goodness of fit value (GoF) is below 4, and the refinement profile (Rp) are below 20. Table 4 is crystal data and structure refinement for $\mathrm{DMH}$. The value $\mathrm{Rp}$, Rwp, and GoF on Table 4 was the best fitting provided by the writer, although it is still above the standard. $\mathrm{DMH}$ caking have $\mathrm{Rp}=21.33$, $\mathrm{Rwp}=29.01$ and $\mathrm{GoF}=$ 207.12\%. Meanwhile, $\mathrm{DMH}$ non-caking have $\mathrm{Rp}=$ 25.03 , Rwp $=33.11$ and $\mathrm{GoF}=266.86 \%$. It means that DMH caking and non-caking are not exactly the same as DMH Hough et al. [29]. Table 4 shows the cell parameters of DMH Hough et al were $\mathrm{a}=8.803000 \AA, \mathrm{b}=5.085000$ $\AA, c=9.708001 \AA$ and $\alpha=\gamma=90.00^{\circ}, \beta=97.67^{\circ}$. The cell parameters of DMH caking were $\mathrm{a}=8.774318 \AA \mathrm{A}, \mathrm{b}=$ $5.087790 \AA, c=9.719185 \AA$ and $\alpha=\gamma=90.00^{\circ}, \beta=97.76^{\circ}$.

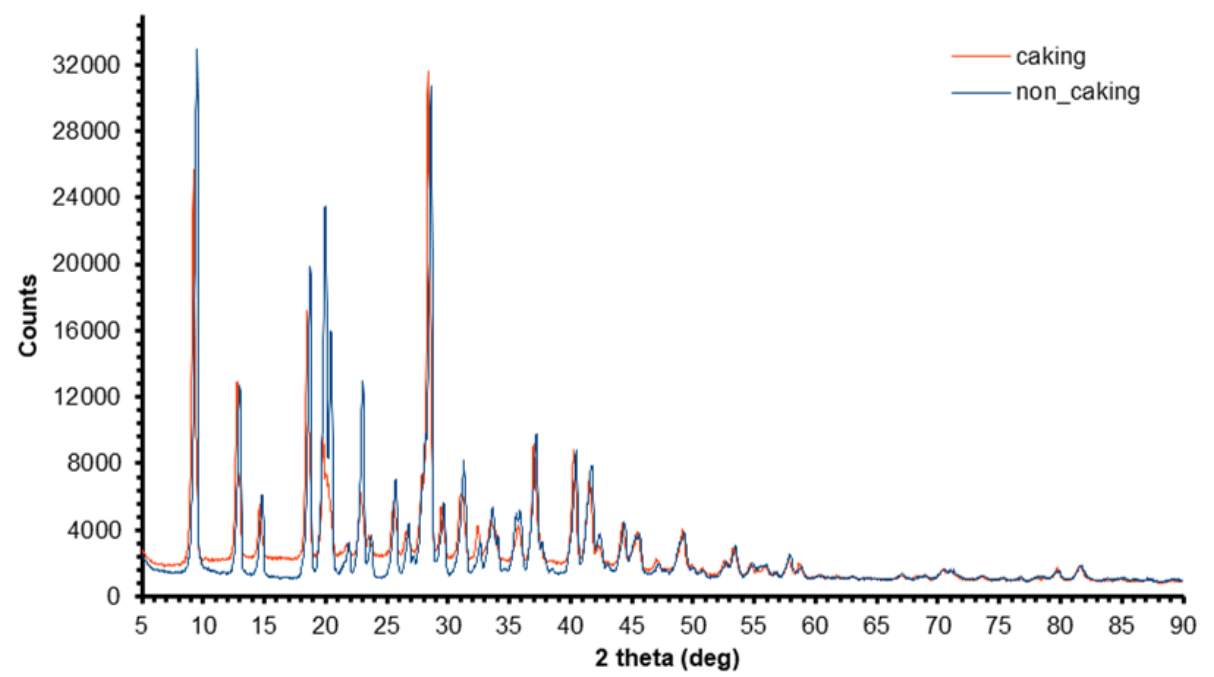

Fig 10. XRD analysis on DMH caking (K.01.03) and DMH non-caking (K.03.03)

Bayu Mahdi Kartika et al. 


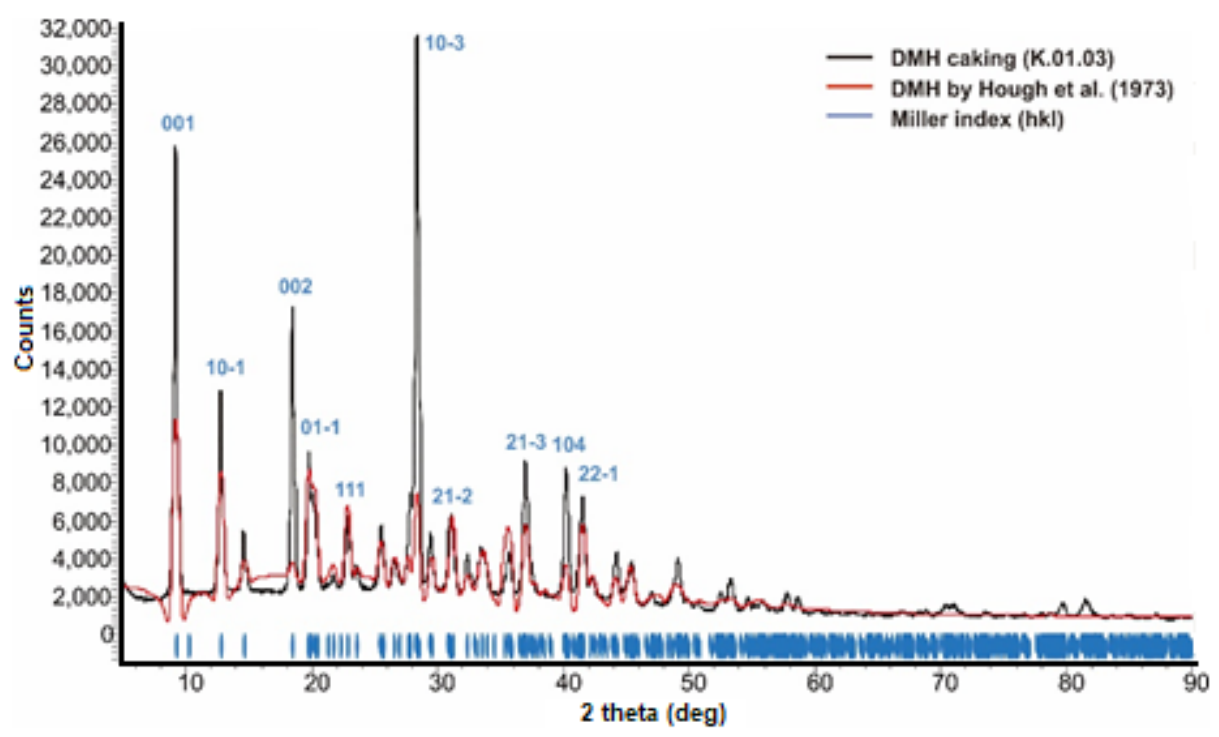

Fig 11. Rietveld refinement analysis of XRD DMH caking (K.01.03) compared to the XRD DMH by Hough et al. [29]

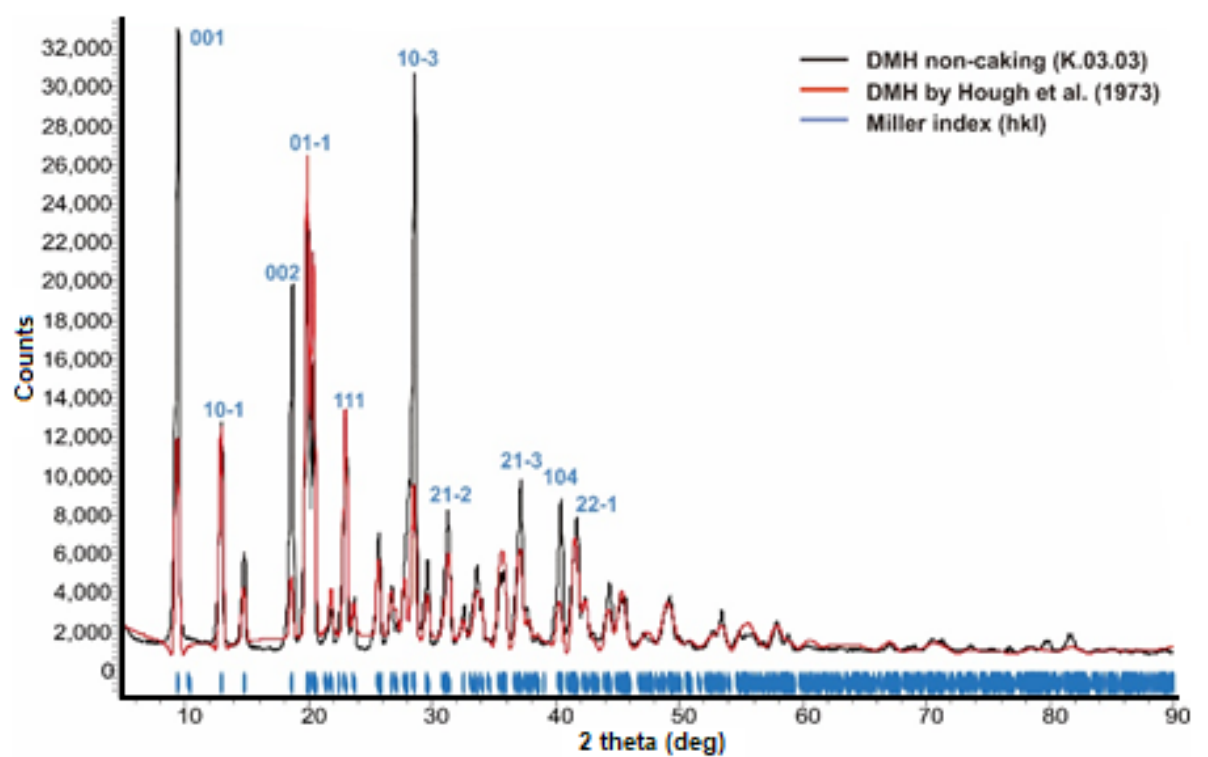

Fig 12. Rietveld refinement analysis of XRD DMH non-caking (K.03.03) compared to the XRD DMH by Hough et al. [29]

The cell parameter of DMH non-caking were $\mathrm{a}=8.816746$ $\AA, \mathrm{b}=5.098714 \AA, \mathrm{c}=9.731324 \AA$ and $\alpha=\gamma=90.00^{\circ}, \beta=$ $97.71^{\circ}$. Based on the vector $(a, b, c)$, angle $(\alpha, \beta, \gamma)$, volume, and density (Table 4 ), DMH caking and noncaking are almost similar to DMH Hough et al. [29], and they have the same peak XRD pattern.

\section{Caking Phenomenon Analysis}

The caking phenomena occur due to the capillary force between DMH particles during on crystallization process [25]. The capillary force is due to the uneven homogeneity of stirring. It is due to the selection of impeller (Rushton turbine) (Fig. 2(a)). Based on the CFD analysis, uneven stirring homogeneity is indicated by low fluid movement $(0-2.571 \mathrm{~m} / \mathrm{s})$ with blue color on the sample solution's surface (Fig. 3(d)). After storing in a closed container for eight weeks, $\mathrm{DMH}$ caking grows fungus (Fig. 7(b)). It is due to the high water content. It is due to the liquid bridge on DMH caking. DMH caking does not meet the standard requirements for DMH food and pharmaceutical grade (Table 1) as it is not powdery (agglomerate), yellow in color, and grows fungus. 
Table 4. Crystal data and structure refinement for DMH

\begin{tabular}{|c|c|c|c|}
\hline Sample & Hough $^{\star}$ & Caking & Non-caking \\
\hline $\mathrm{a}(\AA)$ & 8.803000 & 8.774318 & 8.816746 \\
\hline $\mathrm{b}(\AA)$ & 5.085000 & 5.087790 & 5.098714 \\
\hline$c(\AA)$ & 9.708001 & 9.719185 & 9.731324 \\
\hline$a\left({ }^{\circ}\right)$ & 90.00 & 90.00 & 90.00 \\
\hline$\beta\left(^{\circ}\right)$ & 97.67 & 97.76 & 97.71 \\
\hline$y\left({ }^{\circ}\right)$ & 90.00 & 90.00 & 90.00 \\
\hline Volume $\left(\AA^{3}\right)$ & 430.673787 & 429.910490 & 433.503845 \\
\hline Density $\left(\mathrm{g} \cdot \mathrm{cm}^{-3}\right)$ & 1.527 & 1.530 & 1.518 \\
\hline GoF (\%) & - & 207.12 & 266.86 \\
\hline Rwp & - & 29.01 & 33.11 \\
\hline $\mathrm{Rp}$ & - & 21.33 & 25.03 \\
\hline \multicolumn{4}{|c|}{ * $\quad$ : DMH reference by Hough et al. [29] } \\
\hline \multicolumn{4}{|c|}{ GoF : The goodness of fit } \\
\hline \multicolumn{4}{|c|}{ Rwp : Refinement weighted profile } \\
\hline \multicolumn{4}{|c|}{ Rp : Refinement profile } \\
\hline
\end{tabular}

Optical microscope analysis shows that the caking occurs within four hours of the crystallization process (Fig. 5). DMH caking does agglomeration, while DMH non-caking does not occur agglomeration (powdery) (Fig. 4). SEM analysis shows that both DMH caking and non-caking have a monoclinic crystal form morphology (vector $\mathrm{a} \neq \mathrm{b} \neq \mathrm{c}$, with angle $\alpha=\gamma=90^{\circ} \neq \beta$ ), but in $\mathrm{DMH}$ caking does agglomeration (Fig. 8(a)). Density analysis shows that DMH caking has higher than DMH noncaking (Table 3). FTIR analysis indicates that DMH caking and non-caking have the same peak spectrum pattern, but in DMH caking, the intensity increases at all peaks (Fig. 9). It is due to the DMH caking density value being higher than DMH non-caking (Table 3). The higher density value results in a being higher dextrose concentration. It results in higher intensity of the FTIR spectrum. XRD analysis shows that $\mathrm{DMH}$ caking and non-caking have the same peak diffractogram pattern (Fig. 10). The caking phenomenon in DMH crystallization can be avoided by selecting the impeller (helical ribbon and anchor). The optical microscope, SEM, and density analysis can be used to identify DMH caking, while FTIR and XRD analysis cannot be used to identify DMH caking.

\section{- CONCLUSION}

The impeller selection (helical ribbon and anchor) will produce an even stirring homogeneity to avoid the caking phenomenon. The optical microscope, SEM, and density analysis can identify DMH caking products due to the agglomeration (material density is $1.257-1.350 \mathrm{~kg} / \mathrm{L}$ ), while $\mathrm{DMH}$ non-caking does not seem agglomerate (material density is $0.504-0.708 \mathrm{~kg} / \mathrm{L}$ ). FTIR and XRD analysis cannot identify DMH caking products cause they have the same peak pattern due to DMH noncaking.

\section{- ACKNOWLEDGMENTS}

The authors would like to acknowledge the financial support of the Saintek scholarship from the Ministry of Research and Technology of the Republic of Indonesia for financially supporting this project. We also thank the Centre for Pharmaceutical and Medical of Technology, Agency for Assessment and Application of Technology, South Tangerang, Banten, for providing facilities for this project.

\section{- AUTHOR CONTRIBUTIONS}

Bayu conducted experiments and data interpretation, Harsojo interpreted XRD, SEM, and revised manuscripts, Eriawan interpreted optical microscope analysis, FTIR, and revised manuscripts. All authors agreed to the final version of this manuscript.

\section{- REFERENCES}

[1] Badan Standarisasi Nasional, 2010, Dekstrosa Monohidrat, SNI 4591-2010, Badan Standardisasi Nasional, Jakarta.

[2] Kementerian Kesehatan, 2014, Farmakope Indonesia Edisi $V$, Kementerian Kesehatan Republik Indonesia, Jakarta, 289-290.

[3] USP, 2016, USP 39-NF 34, The United States Pharmacopeial Convention, Rockville Maryland.

[4] Srisa-Nga, S., Flood, A.E., and White, E.T., 2006, The secondary nucleation threshold and crystal growth of a-glucose monohydrate in aqueous solution, Cryst. Growth Des., 6 (3), 795-801.

[5] Zheng, Z.P., Fan, W.H., Li, H., and Tang, J., 2014, Terahertz spectral investigation of anhydrous and monohydrated glucose using terahertz spectroscopy and solid-state theory, J. Mol. Spectrosc., 296, 9-13. 
[6] Frawley, P.J., Mitchell, N.A., Ó’Ciardhá, C.T., and Hutton, K.W., 2012, The effects of supersaturation, temperature, agitation and seed surface area on the secondary nucleation of paracetamol in ethanol solutions, Chem. Eng. Sci., 75, 183-197.

[7] Acevedo, D., and Nagy, Z.K., 2014, Systematic classification of unseeded batch crystallization systems for achievable shape and size analysis, $J$. Cryst. Growth, 394, 97-105.

[8] El-Yafi, A.K.E.Z., and El-Zein, H., 2014, Technical crystallization for application in pharmaceutical material engineering: Review article, Asian J. Pharm. Sci., 10 (4), 283-291.

[9] Jha, S.K., Karthika, S., and Radhakrishnan, T.K., 2017, Modelling and control of crystallization process, Resour. Technol., 3 (1), 94-100.

[10] Besenhard, M.O., Chaudhury, A., Vetter, T., Ramachandran, R., and Khinast, J.G., 2015, Evaluation of parameter estimation methods for crystallization processes modeled via population balance equations, Chem. Eng. Res. Des., 94, 275-289.

[11] Sormoli, M.E., Das, D., and Langrish, T.A.G., 2013, Crystallization behavior of lactose/sucrose mixtures during water-induced crystallization, J. Food Eng., 116 (4), 873-880.

[12] Tappi, S., Laghi, L., Dettori, A., Piana, L., Ragni, L., and Rocculi, P., 2019, Investigation of water state during induced crystallization of honey, Food Chem., 294, 260-266.

[13] Parimaladevi, P., and Srinivasan, K., 2014, Influence of supersaturation level on the morphology of $\alpha$ lactose monohydrate crystals, Int. Dairy J., 39 (2), 301-311.

[14] Markande, A., Nezzal, A., Fitzpatrick, J., Aerts, L., and Redl, A., 2012, Influence of impurities on the crystallization of dextrose monohydrate, J. Cryst. Growth, 353 (1), 145-151.

[15] Markande, A., Fitzpatrick, J., Nezzal, A., Aerts, L., and Redl, A., 2012, Effect of initial dextrose concentration, seeding and cooling profile on the crystallization of dextrose monohydrate, Food Bioprod. Process., 90 (3), 406-412.
[16] Das, D., Wang, E., and Langrish, T.A.G., 2014, Solid-phase crystallization of spray-dried glucose powders: A perspective and comparison with lactose and sucrose, Adv. Powder Technol., 25 (4), 1234-1239.

[17] Markande, A., Fitzpatrick, J., Nezzal, A., Aerts, L., and Redl, A., 2013, Application of in-line monitoring for aiding interpretation and control of dextrose monohydrate crystallization, J. Food Eng., 114 (1), 8-13.

[18] Kartika, B.M., Khojayanti, L., Nuha, Listiana, S., Kusumaningrum, S., and Wijaya, A.F., 2019, Dektrosa monohidrat kualitas farmasi dari pati Manihot esculenta, Metroxylon sagu, Zea mays, Oryza sativa, dan Triticum, J. Bioteknol. Biosains Indones., 6 (2), 184.

[19] Carpin, M., Bertelsen, H., Bech, J.K., Jeantet, R., Risbo, J., and Schuck, P., 2016, Caking of lactose: A critical review, Trends Food Sci. Technol., 53, 1-12.

[20] Langlet, M., Benali, M., Pezron, I., Saleh, K., Guigon, P., and Metlas-Komunjer, L., 2013, Caking of sodium chloride: Role of ambient relative humidity in dissolution and recrystallization process, Chem. Eng. Sci., 86, 78-86.

[21] Freeman, T., Brockbank, K., and Armstrong, B., 2015, Measurement and quantification of caking in powders, Procedia Eng., 102, 35-44.

[22] Afrassiabian, Z., Leturia, M., Benali, M., Guessasma, M., and Saleh, K., 2016, An overview of the role of capillary condensation in wet caking of powders, Chem. Eng. Res. Des., 110, 245-254.

[23] Zafar, U., Vivacqua, V., Calvert, G., Ghadiri, M., and Cleaver, J.A.S., 2017, A review of bulk powder caking, Powder Technol., 313, 389-401.

[24] Chen, M., Wu, S., Xu, S., Yu, B., Shilbayeh, M., Liu, Y., Zhu, X., Wang, J., and Gong, J., 2018, Caking of crystals: Characterization, mechanisms and prevention, Powder Technol., 337, 51-67.

[25] Chen, M., Zhang, D., Dong, W., Luo, Z., Kang, C., Li, H., Wang, G., and Gong, J., 2019, Amorphous and humidity caking: A review, Chinese J. Chem. Eng., 27 (6), 1429-1438. 
[26] Lipasek, R.A., Ortiz, J.C., Taylor, L.S., and Mauer, L.J., 2012, Effects of anticaking agents and storage conditions on the moisture sorption, caking, and flowability of deliquescent ingredients, Food Res. Int., 45 (1), 369-380.

[27] Sinnott, R.K., 2005, Coulson and Richardson's Chemical Engineering, Vol. 6: Chemical Engineering Design, $4^{\text {th }}$ Ed., Butterworth-Heinemann, Oxford, UK.

[28] Flood, A.E., and Srisanga, S., 2012, An improved model of the seeded batch crystallization of glucose monohydrate from aqueous solutions, J. Food Eng., 109 (2), 209-217.

[29] Hough, E., Neidle, S., Rogers, D., and Troughton, P.G.H., 1973, The crystal structure of $\alpha$-D-glucose monohydrate, Acta Crystallogr., Sect. B: Struct. Sci., Cryst. Eng. Mater., 29 (2), 365-367.

[30] Wiercigroch, E., Szafraniec, E., Czamara, K., Pacia, M.Z., Majzner, K., Kochan, K., Kaczor, A., Baranska, M., and Malek, K., 2017, Raman and infrared spectroscopy of carbohydrates: A review, Spectrochim. Acta, Part A, 185, 317-335.

[31] Tokoro, C., Suzuki, S., Haraguchi, D., and Izawa, S., 2014, Silicate removal in aluminum hydroxide coprecipitation process, Materials, 7 (2), 1084-1096.

[32] Sujiono, E.H., Zharvan, V., Poetra, S.A., Muchtar, M., Idris, A.M., and Dahlan, M.Y., 2021, Structure identification of $\mathrm{Nd}_{1-\mathrm{x}} \mathrm{Yb}_{\mathrm{x}} \mathrm{FeO}_{3}(\mathrm{x}=0.01,0.05$ and 0.10) using Rietveld refinement method, Mater. Today Proc., 44, 3381-3384. 